$11-19-2020$

\title{
The masked demos: Associational anonymity and democratic practice
}

Jennifer Forestal

Loyola University Chicago, jforestal@luc.edu

Menaka Philips

Tulane University

Follow this and additional works at: https://ecommons.luc.edu/politicalscience_facpubs

Part of the Political Science Commons

Author Manuscript

This is a pre-publication author manuscript of the final, published article.

\section{Recommended Citation}

Forestal, Jennifer and Philips, Menaka. The masked demos: Associational anonymity and democratic practice. Contemporary Political Theory, 19, : 573-595, 2020. Retrieved from Loyola eCommons, Political Science: Faculty Publications and Other Works, http://dx.doi.org/10.1057/s41296-019-00368-2

This Article is brought to you for free and open access by the Faculty Publications and Other Works by Department at Loyola eCommons. It has been accepted for inclusion in Political Science: Faculty Publications and Other Works by an authorized administrator of Loyola eCommons. For more information, please contact ecommons@luc.edu. cc) (ㅇ) $\Theta$

This work is licensed under a Creative Commons Attribution-Noncommercial-No Derivative Works 3.0 License. (c) Springer, 2020. 


\section{The Masked Demos: Associational Anonymity and Democratic Practice}

The increased use of anonymous digital platforms raises substantive concerns about accountability in digital spaces. However, contemporary evaluations of anonymity focus too narrowly on its protective function: its ability to protect a diversity of speakers and ideas. Drawing on two examples of anonymous political engagements-Publius's writing of the Federalist Papers and college students' use of the social media platform Yik Yak-we develop an account of anonymity's associational function: the processes by which people generate and negotiate collective identities, discussions, and actions in wider publics. As we argue, anonymity's associational function can (1) generate conditions under which individuals develop collective interests and identities to foster collective action and (2) enable novel interactions between these individuals and communities and the larger publics of which they are part. We conclude with a discussion of how attention to associational anonymity can contribute to a more nuanced account of democracy in practice.

Acknowledgements: The authors would like to thank the anonymous reviewers and editorial team at CPT for their helpful comments. They would also like to thank participants at the 2016 Association for Political Theory meeting, where an early version of this article was presented.

\section{Introduction}

On April 28, 2017, the anonymous messaging app Yik Yak announced it was shutting down permanently. Introduced in 2013 by two students at Furman University, Yik Yak quickly gained wide popularity on college campuses. Functioning like a combination of Twitter and Reddit, Yik Yak allowed users to anonymously post short text messages ('yaks') that could be voted 'up' or 'down' by others to signal approval or disapproval. Unlike Twitter or Reddit, or even other anonymous apps like Whisper, yaks were only visible to users within a mile-and-a-half 
geographic radius or a pre-designated 'herd' like a particular college or university. ${ }^{1}$ Yik Yak's 'geo-fenced' design — the fact that messages posted to Yik Yak were only visible to users within one's physical proximity—-prompted some to describe the platform as a "modern day town square" (“College and Yik Yak Partner To Create Unique, Customized Local News Feed” 2015).

Unlike in traditional physical town squares, however, individual Yik Yak users were anonymous to one another. The result was, as one article put it, an app that functioned less as a town square and more like "a virtual bathroom wall at the student union" (Mahler 2015). Following in the footsteps of previous anonymous campus message boards like JuicyCampus, Yik Yak was heavily criticized by students and observers alike for the affordances its anonymity provided, which were thought to enable expressions of injurious speech without accountability (Feminist Majority Foundation et. al 2015). Indeed, even as the app soared in popularity, it soon also "became associated with bullying, discriminatory speech and threats of bomb and gun violence" (Safronova 2017) and, as a result, faced significant backlash. Responding to instances of explicit and aggressive racism and sexism frequently displayed on the platform, for example, students at the College of Idaho, Georgia Emory University, and Clemson University — as well as 72 social justice organizations who petitioned the Office for Civil Rights—denounced the app and requested that it be banned or blocked from campuses across the United States (Safronova 2017). By 2017, after introducing several unsuccessful changes to the app designed to curtail the cyberbullying, threats, and harassment that had become synonymous with Yik Yak, the company folded.

${ }^{1}$ The specific limits of Yik-Yak's geo-fence changed over the app's short life-it ranged from 1.5 to 10 miles (Stoller 2015). 
That Yik Yak's anonymous structure became the target for criticism is unsurprising. Since the early days of the internet, anonymous speech has been viewed with suspicion by scholars of media and technology. Following Suler's (2004) observation that "people say and do things in cyberspace that they wouldn't ordinarily say and do in the face-to-face world" (321), scholars have connected online anonymity and its corresponding 'disinhibition effect' to increased incivility (Rowe 2015), aggression (Rösner and Krämer 2016), and bullying (Bartlett, Douglas, and Chew 2016) in digital spaces. Without the reputational considerations attached to one's real name, this argument goes, anonymous users lack the accountability which keeps bad behavior in check. These criticisms have troubling implications for anonymity's role in democratic politics: if anonymity's functions are entirely captured by its toxic disinhibition effects, its use in public life would seem to be antithetical to productive democratic engagements.

But it is not clear that anonymity is as destructive of democracy as conventional wisdom would have us believe. Indeed, there is a rich tradition in both democratic theory and legal practice that defends anonymous speech and action (Moore 2018; Gardner 2011; Heins 2010). Importantly, however, this defense has been narrowly construed. When anonymity's democratic utility is praised, scholars and practitioners tend to focus attention on what we call anonymity's two-fold protective function: the extent to which it widens the scope of participation in the public sphere by (1) affording marginalized individuals access to public speech or (2) expanding the 'marketplace of ideas' by protecting unpopular perspectives. We saw this protective function play out in defenses of Yik Yak, with organizations like the Electronic Frontier Foundation (2016) arguing that "policies that impede online anonymity...present barriers to speech for marginalized communities and others who fear retaliation for their political or social commentary." 
Anonymity's protective function is certainly an important one—but in its most common form this defense of anonymity is premised on an individualized approach to understanding democratic politics. In both of its manifestations, anonymity's protective frame is focused on securing the presence of individual people or perspectives in democratic discourse. Anonymity, in other words, is understood as valuable for its ability to make the public sphere more inclusive. But the inclusive benefit of protecting individual voices and ideas does not exhaust anonymity's democratic value.

As a collective enterprise, democratic politics requires not just the presence of individual people or ideas; it also relies on forms of engagement and expression that generate investment in communities to which one belongs or aims to belong, both on- and off-line. Just as union organizations can negotiate new perspectives for workers on issues of labor rights and class identity, for example, the rise of Black Lives Matter, Anonymous, and the \#MeToo movement highlights how online platforms enable users to develop and organize political communities (Asenbaum 2018b; Pew Research Center 2018; Cobb 2016). What the protective defense of anonymity misses, therefore, is how anonymity contributes to these collective dynamics-what we call the associational function of anonymity.

This paper aims to develop an account of anonymity's associational function. Beyond its protective uses, we argue, anonymity's associative dimension concerns the processes by which people generate and negotiate collective identities, discussions, and actions as part of wider publics or social spheres. We develop this case in three parts. First, the next section outlines the limits of dominant debates concerning anonymity that focus primarily on its protective function. This focus narrows evaluations of anonymity's potential to individualized issues of access to speech and to enlightened public argument, while bypassing critical questions about the associative practices that 
anonymous interactions can help facilitate. The result is a 'thin' understanding of anonymity's relation to democratic politics — one that can too easily lead to quick condemnation of anonymous forums without fully examining their possible contributions.

Second, the paper turns to recover anonymity's associative practices through two cases: the writing of the Federalist Papers by Publius and students' use of Yik Yak on college campuses. Though separated by time and medium, these cases not only highlight a history of anonymous civic action, but also suggest the ways in which anonymity has long helped to shape collectives around issues of public concern. ${ }^{2}$ As we show, anonymity's associative function is two-fold. It can, first, generate conditions under which communities form the ties of solidarity and mutuality that foster associative action and, second, enable novel interactions between these individuals and communities and the larger publics of which they are a part.

In the case of the Federalist Papers, relinquishing individual credit (and responsibility) for writing moved three individual authors with substantively differing opinions to work collectively under the pseudonym Publius in defense of a new constitution. In the case of Yik Yak, anonymity facilitated various collective engagements, including the unveiling of deeply problematic perspectives, as part of wider contestations over campus communities' values. In both cases, anonymity helped citizens define and internalize common aims and experiences as the basis for new modes of cooperative engagement which rested not on individual, but on collective

${ }^{2}$ Both Publius and Yik Yak are examples of mediated democratic engagements-in which participants do not interact "face-to-face." While the centrality of face-to-face interactions in democratic politics has long been assumed, there is a growing body of literature which explores new modes of deliberative engagement through mediated interactions, including those online (Abernathy et al. n.d.; Iandoli et al. 2018; Neblo, Esterling, and Lazer 2018; Brinker, Gastil, and Richards 2015). 
accountability — whether aimed at ratification or else organized around calling attention to realities of university life. Though the Publius authors knew each other's identities while Yik Yak users only knew that they shared geographic proximity, the underlying dynamics of associative anonymity functioned in similar ways in these cases.

Consider that, even though the Publius authors were not anonymous to each other, the pace of writing the Federalist Papers meant that the authors wrote quite independently - effectively 'posting' each essay on the heels of another. As a result, there was no time for the traditional editing and oversight that might operate in collaborative negotiations between individual authors. Instead of individually holding one another to account, the Papers were shaped by the collective dynamics of associational anonymity, which moved each of the authors to willingly "submerge their real personalities in that of the fictitious 'Publius'" (Adair 1944, 237). As we argue in relation to Yik Yak, these same associative dynamics also moved students to post and act in response to themes of collective responsibility - from mental health to hostile campus climates. For both Publius and campus Yik Yak users, anonymity shifted participants away from their individual inclinations and towards the negotiation of public issues through the identification and articulation of shared concerns or experiences.

Our argument, however, should not be taken to suggest that anonymity is wholly unproblematic. It can have troubling results. For instance, what do we make of collectives that form, discuss, and defend exclusionary policies or even anti-democratic proposals for institutional reform? It is certainly the case that Publius's arguments held anti-democratic elements, while Yik Yak hosted undemocratic and exclusionary views. We thus do not take these cases (or the US context in which they unfolded) to be exemplary democratic engagements. Rather, we view them 
as instructive examples of anonymity's associative function and its relation to the challenges of practicing democracy.

Finally, we conclude with a discussion of how attention to anonymity's associative function can help to develop a more nuanced account of democracy in practice. Associative anonymity (whether on- or offline) can be useful for democratic politics insofar as it facilitates the formation of collectives in which participating individuals operate. But as with the inclusive dimensions of anonymity's protective frame, though associative anonymity is necessary, it is not a sufficient condition for democracy. Instead, both the utility and challenges of associative anonymity should cue us to the complexities involved with doing democratic politics.

\section{Anonymity's Protective Tradition}

Though recent controversies over the public value of anonymity, prompted by anonymous online spaces like Reddit, 4chan, and Yik Yak, tend to treat anonymity as a unique function of digital technologies, the practice of concealing one's identity in public interactions has a long political history. In the United States, Thomas Paine signed Common Sense as "An Englishman" and William Lloyd Garrison wrote as "Aristides," while Portuguese poet and political analyst Fernando Pessoa published under nearly 75 different nom de plumes. In Europe, the use of pseudonyms for controversial publications was widespread, from writers like Voltaire, Marquis de Sade, George Sand, and the Danish philosopher Søren Kierkegaard, to the English context in which Ned Ludd protected the Luddites and John Locke anonymously published the Second Treatise.

With such a rich and extended history, scholars have been attentive to the political effects of anonymity, discussing its consequences for voting behavior (Mill 1977) as well as its effects on democratic citizenship (Gardner 2011) and communicative accountability (Moore 2018). 
Likewise, there is a growing body of research that explores anonymity's role in campaign finance (Dowling and Wichowsky 2013; Ridout, Franz, and Fowler 2015). And scholars have more recently turned their attention to examine anonymity in digital spaces, outlining the new modes of political activity opened by online anonymity (Wong and Brown 2013; Asenbaum 2018a).

Across this work, however, anonymity's democratic utility has largely been defended in terms of what we call its 'protective' function, drawing from two major principles in democratic theory. First, based on the principle of inclusion, anonymity is recognized for protecting those populations otherwise vulnerable to retribution, thereby facilitating the participation of a greater number of individuals in public life (Cullinane 2011; Ekstrand and Jeyaram 2011). As democratic theorists have long noted, there are serious structural barriers to participation that often get in the way of inclusion - particularly where marginalized groups are prevented from speaking (Lupia and Norton 2017). Anonymity, then, is democratically useful insofar as it protects such individuals by removing the threat of retribution or by obscuring physical cues that might bias receptions of their speech. In the contemporary context, anonymous digital technologies can free users from "socio-economic inequalities and social constraints," which afford them more equal opportunities to share "in the personal freedom to choose how to express themselves" (Leitner 2015, 206).

The logic of inclusion appears throughout first amendment defenses of anonymous speech in US law. NAACP v. Alabama (1958), for example, protected anonymous speech by overruling the state of Alabama's attempt to force the state chapter of the NAACP to disclose its membership rosters. In a unanimous opinion, the Court held that effective advocacy on behalf of political minorities is often enhanced by anonymity because it ensures that vulnerable voices can speak about and contribute to social and political life without fear of retribution. The protective function of anonymity, in other words, has the effect of evening the playing field, acting as a conduit that 
allows marginalized individuals to enter the public sphere. As such, it provides a mechanism for widening access to the rights of speech and thereby enhances civic inclusion.

Second, for those encouraging diverse perspectives to enter the public sphere (in the tradition of JS Mill and others), anonymity is lauded to the extent that it can protect a wider array of arguments. As a conduit for diverse and sometimes subversive and unpopular viewpoints, anonymity protects dissident positions in the "contestation of hegemonic power structures" that control state and society (Asenbaum 2018a, 465). Historically, as the US Supreme Court has recognized, anonymous pamphlets and books "played an important role in the progress of mankind" such that unpopular groups "have been able to criticize oppressive practices and laws either anonymously or not at all" (Talley v. California 362 U.S. 60 1960). And again, in the digital context, access to anonymous digital platforms has been central to the work of political activists, dissidents and human rights organizations aimed at exposing social injustices and government abuses (Akdeniz 2002). Anonymity here protects not only the speaker, but the dissemination of ideas and arguments that may be critical to social progress. This diversifying value of anonymity's protective function is used to justify contemporary academic peer review practices, as well as instances where anonymity affords authors the ability to write more freely or candidly about private matters (Barendt 2016). While protective anonymity may allow lesser arguments to enter the public sphere then, the expansion of ideas procured by anonymous speech is worth that cost.

The inclusion offered by anonymity's protective frame is no doubt essential to challenging discriminatory and myopic politics; it therefore bears an important role in evaluations of anonymity's utility for democracy. Yet focusing on inclusion alone, whether of people or ideas, fails to account for the whole range of activity involved in democratic politics. Indeed, evaluating anonymity's democratic potential through the inclusively oriented protective frame often leads to 
analyses focused on the presence of ideas or individuals: does anonymity facilitate the inclusion of more voices or fewer? Which arguments should be protected?

These questions, however, address neither the ways in which people speak and act with each other nor the problems of trust and political backlash which can arise when publics do grow to encompass individuals and perspectives that challenge the status quo (Arneil 2010, 282-83). Consequently, alongside the presence of people and ideas, democracy also requires attention to the collective behaviors of speakers - to the associational practices that underwrite democratic politics. As we suggest, by drawing out anonymity's associative function we can expand the evaluative criteria with which to understand and judge anonymity's democratic potential.

\section{Anonymity's Associational Function: Examining Two Cases}

As political theorists have long noted, democratic publics are not made up of individual actors alone; instead, democratic discourse often takes place both between and within groups (Warren 2001; Putnam 2000). Beyond the mere presence of individuals and ideas in public, associative practices catalyze collective identity formation and shape the discussion and negotiation of competing positions within broader publics. Thus, these associative practices are two-fold. First, democracies require the construction of collectives: citizens must come to understand themselves not in isolation, but as part of an association that "unites the energies of divergent minds" (Tocqueville 2006, 190) around a particular issue. By engaging in certain practices-like eschewing individual credit-taking - those united energies contribute to the formation of a collective identity (Allen 2015).

Second, once formed, collectives not only negotiate internally, but also interact with the broader publics of which they are a part. These ongoing processes of negotiation and contestation 
within and between collectives - including attempts to reshape the broader public within which all groups operate - form the basis of democratic deliberation (J. Dewey 1946; Mill 1977). Alongside the inclusion of individuals and ideas, therefore, democratic politics necessitate the formation of groups and their continued negotiation with other publics.

Despite these collective dimensions of democratic politics, discussions of anonymity's effects on democracy have largely overlooked its associative potential (Boyd and Field 2016; Saveski, Chou, and Roy 2016; Boudin 2011; Cullinane 2011). This elision in the scholarship belies the fact that anonymous civic engagements have long been "indispensable to the preservation of freedom of association" (NAACP v. Alabama Ex Rel. Patterson 357 U.S. 449 1958). From the Boston Tea Party (1773) to the Ku Klux Klan (1856-), from the Combahee River Collective (1974-1980), to the Redstockings (1969—), Pussy Riot (2011), and Anonymous (2003—) we see the associative dimensions of anonymity - and its attendant tensions - play out again and again in political life. Just as anonymity can facilitate inclusion by protecting vulnerable individuals or unpopular ideas, so too can it help to generate the conditions under which individuals associate to not only form collectives, but also to interact as part of those collectives with a larger public in ongoing democratic processes of discussion, negotiation, and debate.

In order to explore anonymity's role in these associative democratic practices, in this section we examine two cases of anonymous democratic engagements: The Federalist Papers written by Publius, and the online platform Yik Yak. Though they differ in terms of historical context, medium, and aims, there are nevertheless notable parallels between the two cases. Both Publius and Yik Yak users operated within largely unregulated and "uncivil" public spheres, where individuals were able to speak freely — and often offensively — without repercussion (Mahler 2015; 
Shalev 2003). Additionally, anonymity's role in both cases has largely been limited to discussions of its protective function.

But while protecting vulnerable speakers and unpopular ideas certainly describes part of anonymity's role in the formation of Publius and in student uses of Yik Yak, in both cases anonymity also facilitated productive associational practices of collective formation and negotiation. For instance, while Yik Yak gained much attention for the racist behavior it hosted, it also provided a mechanism for students to forge community support around issues like mental health and discrimination. Likewise, Publius is still widely recognized for its critical contribution to debates concerning democratic life and governance - from the nature of elections to the burdens of citizenship. By examining these cases through the lens of anonymity's associative function, we can more clearly articulate anonymity's associational possibilities - both in terms of its democratic value as well as the challenges of democratic practice which it reveals.

\section{Publius and Associational Writing}

For scholars of American political thought, the Federalist Papers represent a pivotal intellectual enterprise. In the years since the Papers were originally written and debuted to the public, they have been the subject of criticism, scrutiny, and praise and have taken their place alongside the Constitution as venerated founding documents (Ball 2003). As a result, there is excellent scholarship unpacking the argument of the Papers (Scigliano 2000; Abbott 1996; Furtwangler 1984), placing them into their proper socio-political context (Boudin 2011; Ekstrand and Jeyaram 2011; Shalev 2003), and showing how the Papers, and other essays like them, contributed to the development of the American public sphere (Frank 2009; Warner 1992). 
By contrast, comparatively little scholarly attention has been paid to the fact that the three authors of the Papers, along with so many of their interlocutors, chose to render themselves anonymous by way of a pseudonym in order to engage in political debate. The pseudonymous authorship of the Papers in fact reflects a long-standing practice of anonymous expression in the Republic. Outside the halls of the constitutional convention, the debates between Federalists and the Anti-Federalists largely engaged the American public by way of anonymously written articles and pamphlets (Shalev 2003).

Without doubt, the protective role of anonymity partly accounts for the conventions of anonymous public writing at the time the Papers were being written. Only a decade out from declaring independence, and only four years from the end of the Revolutionary War, those involved in the ratification debate were staking their political—and personal—reputations on a risky endeavor. The ratification debate invited a "passionate and emotionally charged atmosphere" in which sometimes unpleasant personal attacks and "libelous remarks" appeared as often as wellreasoned arguments (Ekstrand and Jeyaram 2011, 39). Federalists and Anti-Federalists both drew on 'inflammatory words such as 'conspiracy,' 'evils,' 'wicked,' 'infamy,' 'tyranny,' and 'slavery" in the course of public debate $(2011,40)$. Absent an easy link between author and argument, the use of pseudonyms protected authors on both sides of the debate from the negative legal and personal consequences of these effective, but unsavory, rhetorical strategies (Cornell 1999).

The biographies of Publius certainly speak to these protective interests. Consider that while Alexander Hamilton, James Madison, and John Jay-the authors that wrote together under Publius - were already well-known at the time they wrote the Papers, they were not necessarily well-loved. Hamilton, in particular, had a habit of publicly engaging in inflammatory personal 
attacks. Not long before the publication of Federalist \#1, Hamilton had embroiled himself in a very public political dispute with George Clinton, during which ad hominem attacks and unsubstantiated rumors flew fast and furious-including attacks on Hamilton's ambitions and character (Chernow 2005). Such accusations would of course frame any reader's reception of a defense he presented of the new Constitution. By engaging in the common practice of using pseudonyms, however, Hamilton, Madison, and Jay intentionally separated their personal proclivities and reputations as individual actors from the arguments they were making collectively as Publius.

But even as protective anonymity safeguarded Hamilton, Madison, and Jay in some measure, it does not fully explain their decision to write together as Publius. There was, of course, a practical dimension to this choice: writing together allowed Hamilton to share the burden of the project. The magnitude of Hamilton's vision for the Federalist Papers is staggering. Even with the original plan of only 25 essays, the truncated time frame and sheer number and geographic spread of newspapers Hamilton hoped to reach made this an ambitious project. To complete it, Hamilton was forced to enlist others to help him. The co-authorship of the Federalist Papers was, in part, a result of strategy.

Yet if he was simply concerned about practicality, Hamilton could just as easily have persuaded Madison and Jay to write independently under their own pseudonyms. And Madison did publish separate essays supporting the new Constitution under his own name (Boudin 2011). The effect in either case-flooding the press with arguments in favor of the Constitution and protecting their identities - might have been the same. But, in deciding to write as Publius, the three collaborators clearly saw an additional value beyond the mere presence of their individual voices. That value has an associative dimension: Publius and the Papers were the products of a 
new collective, the Federalists, which sought to reshape the nascent American republic through acts of democratic writing (Allen 2015). The Papers were a cooperative effort aimed at swaying "public sentiment in favor of the Constitution just as it was coming to a vote in each state," taking apart counter arguments with "remorseless logic" (Allen 2015, 102). Beyond the protection of the individual authors, anonymity provided the means by which that new collective, and its now renown engagements with the American public, could emerge.

\section{Publius and the formation of a Federalist collective}

Though most scholarship today — as well as most printings of the texts themselves—name Hamilton, Madison, or Jay as the authors of each individual essay of the Federalist Papers, the essays were originally disseminated to the public under a single pseudonym: Publius. Noting this, Jason Frank (2013) argues "The Federalist was not written to provide a definitive articulation of the political thought of its three authors... but instead to rhetorically achieve a single public goal: the ratification of the proposed federal constitution" (19). In attributing individual authorship for each essay, in other words, scholars have in effect misattributed the Papers; even Hamilton and Madison, when corresponding with one another, went to great lengths to maintain their anonymity, referring to the Papers "as though 'Publius' were some third and unknown person" (Adair 1944, 237). Notably, even after their identities were revealed by a French collection of the essays in 1792, Hamilton refused to allow an American publisher to reprint and assign the essays to individual authors - though ratification had succeeded years earlier (Adair 1998). As a result, "Scholars who seek the original intent of Publius in the personal authorship of Hamilton, Madison, and Jay... violate Publius's own guidelines for establishing the meaning of his text" (Frank 2013, 20). The rhetorical effect of the Papers which Frank recognizes here highlights the first of anonymity's associative functions at work. Writing together as Publius reshaped the three authors' 
individual orientations towards their collective project as 'Federalists:' developing a case for a new constitution.

It is no secret, after all, that Madison and Hamilton had differences of opinion on the merits of the Constitution, as well as ideas as to its proper implementation. Those disagreements were voiced publicly at the Philadelphia Convention, highlighting "markedly divergent plans for the formation of the new union" (Adair 1944, 241). Their ongoing disagreements about interpretations of the constitution - particularly around issues of participatory democracy and economic policy came to a head in the years after the ratification, and "severed the Roman alliance [Publius] of 1787-88" between them (Sheehan 2004, 406). But with the Papers, the authors subsumed their differences under a singular voice that did not exist prior to the invention of Publius. By working anonymously under the sign Publius, these divergent minds became accountable to a collective aim, ratification, "and laid aside all differences in order to bring this about" (Adair 1944, 241).

Writing anonymously, Hamilton, Madison, and Jay were able to adapt themselves to the process of what Danielle Allen calls democratic writing, which develops "collective intelligence and does not seek credit. It does not know intellectual pride" (Allen 2015, 103). Unified as Publius, Hamilton, Madison, and Jay compromised their individual perspectives and re-oriented themselves towards the single, sustained, and cohesive Federalist argument; as a result, they "were all agreed that the effect of 'Publius' would be augmented if the names of the actual authors remained unknown" (Adair 1944, 236). Publius thus cultivated a novel authorial relationship within their Federalist collective that was, in many ways, a departure from each author's individual position.

While neither Hamilton nor Madison or Jay surrendered their personal opinions on political questions in other writings, as Publius they acted collectively. They had to position themselves outside their routine perspectives, personal foibles, and engage in what Linda Zerilli, following 
Hannah Arendt, terms "representative thinking" (Zerilli 2009; Arendt and Kohn 2006). Though we can still see evidence of these tensions in the differences between individual essays in the Papers, they are much less obvious than if the essays were presented as wholly separate texts. And importantly, for the public reading them at the time, absent knowledge of the authors' identities, those differences would have been difficult to evaluate. Indeed, as Douglas Adair notes, at the time the essays were published "there were probably not a dozen individuals who definitely could state that Hamilton, Madison, and Jay had written" the Papers (Adair 1944, 238). The result was a series of essays that were more widely accessible for audiences in the nascent republic — not merely because the identities of the authors were concealed, but also because the Papers synthesized multiple perspectives to present a cohesive argument for constitutional ratification to the wider public.

\section{Publius and the American Public}

In addition to facilitating Hamilton, Madison, and Jay's ability to think of themselvesand write — as members of a cohesive 'Federalist collective,' anonymity also opened novel ways for Publius, and other writers of the time, to engage with the American people. As scholars like Michael Warner have noted, the anonymous writing of the early US republic had an important effect in reshaping the authors' identities as participants in the fledging national public sphere. “Anonymity," Warner (1992) argues, "in the republican culture of print, designates not cowardice but public virtue" (108). Likewise, in his comprehensive edition of the Papers, Terrance Ball shows that the essays, read alongside Anti-Federalist printings in the same period, reveal the "dialogical dimension of the ratification debate in which The Federalist Papers played such a

prominent part" (Ball 2003, xi). The anonymity provided by 'Publius' and other pseudonyms bolsters this view, and nods to the aspirations of democratic writing "to write to any and for all, 
for any and all" (Allen 2015, 91). The Papers, Publius argued in Federalist \#1, were intended to "be open to all and may be judged by all. They shall at least be offered in a spirit which will not disgrace the cause of truth" (Ball 2003, 4). By separating their personal identities from their political arguments in the Papers, the authors' use of 'Publius' worked to highlight the essays as a work of 'public reason' and to appeal to an emerging American public on the basis of the authors' "rational and disinterested concern for the public good" rather than their personal self-interest (Warner 1992, 42). Thus, writing as Publius not only protected the authors from retaliation and facilitated the formation of a distinct collective identity, it also effectively allowed them to reach a wider set of readers in a distinct rhetorical mode.

This is particularly significant considering the intense state-centrism and rivalries at the time of the constitutional debates. Writing anonymously let Publius sidestep the state antagonisms that might otherwise have colored the receptions of any individual arguments presented by Hamilton, Madison and Jay, and to speak to a broadly American audience at a time when the American public, indeed the identity of the United States itself was just being forged. Associative anonymity in this case helped Publius contribute to a highly fraught deliberation over the principles and aims of an emerging nation. It was a critical mechanism in their effort to make arguments that were 'open to all' so that they might be 'judged by all.'

Joined together, the inclusionary work of the protective frame and the collaborative work of the associational frame map out the layered democratic utility of anonymous civic practices. The associational processes embedded in cases like Publius — and of anonymity more generallycannot be fully captured when one approaches it only from the frames of protection for individual authors or arguments. In addition to providing protection, 'Publius' also created an associational space which altered the individual authors' orientation to their collective aim in novel and 
productive ways. As Madison later wrote, the endeavor of writing the Papers was an act that was "carried on in concert" but one in which "the writers are not mutually answerable for all the ideas of each other" (Adair 1944, 240-41). Writing as Publius created a mechanism through which the authors held themselves to account—and did so using the aims of the Federalist collective.

Writing as Publius thus shifted the dynamics of authorship and accountability involved in the Papers. The individual authors' accountability to each other did not drive their work; rather, the force of 'Publius' constructed a collective accountability which constrained their individual preferences by means of their shared intention to shape public discourse towards a larger goal. And writing anonymously enabled Publius to engage with the broader American public with a novel rhetorical effect. Using the associational frame, we can therefore better understand how anonymity can help individuals to form new collectives and renegotiate their positions within the broader publics of which they are a part- two key elements of democratic politics. The use of associational anonymity thus provides a distinct conduit through which individuals can channel their perspectives and labor into a cooperative endeavor.

\section{Yik Yak and the Unveiling of Campus Cultures}

Traditional focus on anonymity's protective function has obscured our understanding of key instances of anonymous democratic activity like the Federalist Papers. Working within the individualized protective frame, the Papers have largely been de-anonymized (since the need for protection no longer holds) and treated as a collection of individually authored essays rather than as the unique associative endeavor the authors understood it to be. As a result, scholars have largely overlooked the ways in which writing anonymously afforded Hamilton, Madison, and Jay a unique space (through Publius) to generate a distinctive collective voice and identity to speak for the Federalist position and enabled a critical, dialogical practice within the new American public 
sphere. But while the associational dynamics of working anonymously as Publius have been undertheorized, the hallowed place the Papers have taken in American history has kept the political import of the authors and their work alive. In contrast, the political insights that can be drawn from the case of Yik Yak have largely been obviated by a failure to consider the operation of associative anonymity and its effects on the platform.

Instead, after Yik Yak was implicated in numerous instances of hate speech and threats on various college campuses, discussions over the platform's merits were largely conducted in the protective frame; conventional wisdom regarding Yik Yak was that its anonymous environment was being used to provide cover to a few 'bad apples.' Though its defenders argued that the unsavory comments that appeared on the platform were a worthwhile price for ensuring a robust and inclusive public sphere, the platform's critics claimed that anonymity's protective potential was being corrupted. Rather than protecting the marginalized or vulnerable, Yik Yak's anonymity acted as a shield for the wrong people, protecting users against the consequences of their discriminatory speech.

Though these arguments about Yik Yak's protective merits spoke to questions about who and what to include in democratic discourse, they once again obscured other salient questionslike how Yik Yak's anonymity changed its users' practices. When we apply the associational frame of anonymity to the case of Yik Yak, by contrast, it draws attention to the ways in which the platform's anonymity contributed to the formation of publics that would not have otherwise recognized themselves as such. Just as anonymity facilitated Hamilton, Madison, and Jay's ability to, as Madison noted, act in concert without being "mutually answerable," so too did Yik Yak's anonymity help users identify latent publics amongst other users in their geographic proximity without the use of 'real names.' Furthermore, once formed, these publics used the anonymous 
spaces of Yik Yak to negotiate their positions with their wider campus publics in new ways. The anonymity of Yik Yak, in other words, facilitated a renegotiation of campus identities and forced universities to confront the experiences and perspectives which shaped campus life.

\section{Yik Yak and the formation of campus collectives}

Coverage of Yik Yak's popularity tended to describe the platform in terms of what students were posting. Though much of the platform's press coverage emphasized the number of threatening, hateful, or harassing messages, others noted the general mundanity of Yik Yak posts: "Imagine," wrote one Washington Post article, "an endless scroll of gems like 'party at TKE tonight' or 'gonna fail my econ midterm today"' (C. Dewey 2014). This emphasis on the content of messages is typical of analyses of anonymous activity conducted within the protective frame. When anonymity's democratic value is predicated solely on what ideas or individuals it enables to enter the public sphere, evaluations of anonymous spaces are limited to this dimension as well.

But this picture of Yik Yak — as a bulletin board or bathroom wall—-does not fully capture the democratic potential of the platform. Recall that Yik Yak allowed for synchronous and geosynced activity, meaning that users could engage in real-time with others who they knew were physically proximate to them and who were, therefore, members of their campus communities. As a result of this unique architecture, Yik Yak's anonymity was able to cultivate collective identities and actions that other anonymous modes of discourse - like a bathroom wall — might not. As one University of Buffalo student noted: "Many people at UB use Yik Yak to express their thoughts and feelings... Yik Yak shows us when other people [are experiencing] or feeling the same way that we do, which is pretty cool" (C. Dewey 2014). As a space to discover and interact with others who shared similar interests and experiences, in other words, Yik Yak enabled students to connect to their peers in novel ways. Indeed, as one reporter noted: “the intimacy of [Yik Yak's] 
geolocation feature inspires a communal vibe...taken together, falling into the Yik Yak feed has the effect of opening an emotional connection with the people around you. That can serve as a powerful antidote to the alienation of a big city (or a massive college campus, or an oppressively cliquey high school” (Hess 2015).

Yik Yak users were both known and unknown to each other: they participated on the platform as members of a commonly recognized campus community, even as they remained individually anonymous. Thus, the platform was well-positioned to develop these unique emotional connections that helped users identify smaller collectives online that were premised on specific shared interests or experiences. Students suffering depression and loneliness, for example, were able to articulate those feelings anonymously on the site - and that articulation catalyzed associative processes within the platform itself. After one "anonymous Michigan student expressed suicidal thoughts on Yik Yak," for example, "the campus responded with a flood of supportive [Yik Yak] messages like 'Stay alive for the amazing person you're becoming' and 'I attempted suicide in October, but never told anybody. It makes me feel better seeing everybody support people in the same boat as me"” (Hess and Chotiner 2015).

Yik Yak's anonymity thus afforded students more than the ability to express their individual opinion on a topic; it also allowed them to identify shared experiences or concerns and to generate collectives like impromptu support groups. Such opportunities highlight the beneficial ways in which group interests and identities could be generated within the associational space constructed by the site. Noting Yik Yak's geo-fence, moreover, some campuses actively tried to use these associative elements of the app to develop a local newsfeed for students which they argued could speed along incident notifications and better represent and promote activities of interest to students (Junco 2015). In one such instance, anonymous posts about LGBT 
discrimination at a local club prompted Duke students to organize a series of kiss-in protests outside the venue (Ramkumar and Chason 2015).

As was the case with Publius_-which facilitated the 'Federalist collective'—Yik Yak's anonymity afforded students the opportunity not just to express their individual opinion, but to place themselves in broader issue-based collectives. The anonymous space of Yik Yak allowed students to form alliances, build communities, and to respond to particular events or experiences that deeply impacted campus life. Associational anonymity here translated the energies of 'divergent minds' into collective enterprises that tackled concerns that they believed demanded wider campus attention.

\section{Yik Yak and the renegotiation with broader campus public}

Yet anonymity's role in forming collectives around experiences like mental health were not what captured media attention when Yik Yak's merits were being debated. It was, rather, the highly offensive statements made by some students against marginalized populations. From racist and misogynist comments, to threats of violence, Yik Yak's infamy arose as a result of the distinctly anti-democratic sentiments targeted at marginalized students. Again, however, these statements were largely assessed within the protective frame - in terms of individual users and their messages. Consequently, the solutions proposed by observers were to either silence speakers by banning the app, or for listeners to stop being offended in the interest of free and open speech. In either case, these debates disavowed the collective nature of the space in which those comments were made, focusing instead on the merits of allowing or banning offensive and violent speech. In doing so, debates over Yik Yak not only ignored the formation of collectives facilitated by anonymity on the app, they also failed to recognize the ways in ways in which such collectives

formed in response to discriminatory posters and messages, and forced their campuses to 
renegotiate uncomfortable realities about the university environment. By attending solely to the inclusion/exclusion of 'bad apples' and messages, evaluations of Yik Yak missed associative anonymity's role in both the formation and negotiation of collectives on campus.

Within the associational frame, the expressions of intolerance on Yik Yak should not have been understood as the isolated opinions of individual sexists or racists. Indeed, as women and students of color rightly pointed out in response to a series of incidents at the University of Missouri, the explicitly sexist, racist, and violent comments on Yik Yak forums did not simply reflect the individual attitudes of a few outlying users. Rather, those forums revealed campus climates that were hostile and aggressive towards certain groups - a reality that was quickly confirmed by many members of the targeted groups in question, and which could not be easily dismissed by administrators as being 'non-representative' of campus cultures (Forestal and Philips 2016; Wethers 2016; Hayes 2014). Just as Publius and other pseudonyms in the early American republic allowed for novel forms of negotiation between individuals, collectives, and the broader American public, then, so too did Yik Yak's associative anonymity also allow users to engage with their wider campus publics with more argumentative force than would be available to them as individuals writing alone. By providing a space where users could find others of like-mind, as targeted students rightly noted, Yik Yak inadvertently helped to push the undercurrent of existing prejudicial perspectives on campus into the open.

And this had real effects, both offline and on the platform. Discriminatory comments on Yik Yak generated online collectives which took up the task of disavowing the posters' views. As one observer noted:

Even the "Don't go to campus" threat [by a would-be mass shooter at the University of Missouri] received comments like "If that is a threat it is completely inappropriate" and "Please don't say things like that." And current uncomfortable discussion (for example, 
highly upvoted reminders that nonminorities have problems, too) could be seen as negative but at least gives the students a forum for open conversation about race. It is also providing insight to Missouri administers and faculty that they wouldn't otherwise have (Fiesler 2015)

Moreover, as these discussions on the platform became widely known, they prompted offline student protests, in Mizzou's case precipitating a threatened strike by its football players, and ultimately the resignation of a university president (Maese and Babb 2015; Larimer 2015). This kind of collective politics was a critical but overlooked element of student engagements on the platform itself.

Where Publius was engaging with the broader American public sphere, in other words, Yik Yak users were responding to, and interacting with, their wider campus publics. And though the issues being debated in Yik Yak's case was often less savory-white supremacy rather than constitutional ratification-we might see in these Yik Yak engagements the legacies of racial slavery that Publius negotiated into the Constitution. The ratification debates were, after all, fraught with the inequities of racial slavery. One of Publius' foremost critics, the pseudonymously named 'Brutus,' argued that the Federalists had conveniently left aside the fact that in accepting slavery, they worked "in defiance of benevolence, justice, and religion, and contrary to all the principles of liberty, which have been publickly [sic] avowed in the late glorious revolution" (Ball 2003, 455). Though centuries lie between them, the high-minded politics of ratification and the contested speech on Yik Yak together reflect America's long imbrication with the politics of race and racism.

Yik Yak's anonymity_like that of Publius — critically shaped the ways in which different online collectives interacted with the broader publics they were part of. The question campus administrators and observers in general ought to have considered in their debates over Yik Yak's democratic utility was not whether to ban the app, but instead how to facilitate the platform's 
associational function in ways that bolstered collective investments in inclusive campus climates, against countervailing efforts to co-opt and appropriate that function for discriminatory speech. Had more campus administrators approached the platform through the lens of association, they may have recognized how it was being used to form alliances around both inclusionary and discriminatory interests, as well as what anonymous associations reflected about their larger campus cultures.

\section{The Masked Demos}

Despite the demise of Yik Yak, anonymity continues to be a critical feature of popular social media platforms from Twitter to Reddit; the proper relationship between anonymity and the democratic public sphere therefore remains a pressing issue for democratic theorists and citizens alike. Yet the contours of this debate are too often shaped by what we call anonymity's protective function: the idea that anonymity is beneficial for democratic politics only insofar as it (1) protects vulnerable populations from retribution, and (2) contributes to the diversity of ideas in the public sphere. Though the protective frame speaks to issues of inclusion - both of individuals and arguments - it cannot capture the processes by which those individuals and arguments interact. To read anonymity only in its protective role, therefore, locks us into an individual-level analysis.

But to understand instances of anonymous democratic action, whether by Publius or Yik Yak users, as merely an aggregate of individual actors is to miss the ways in which the anonymity facilitates the kinds of associative practices necessary for democratic politics. In any discussions of anonymity's democratic utility, its two-fold impact on associational processes must be considered. First, as we have argued, anonymity facilitates the cultivation of distinct collective identities. Recalling the formation of the Combahee River Collective (CRC), for example, Demita 
Frazier notes that the decision to work under the pseudonym reflected a desire to "be a collective and not a hierarchical organization because it was antithetical to our beliefs about democracy and the need to share" (Harris 2001, 9). Named for the Combahee River, where Harriet Tubman had collaborated with the Union Army to help escaping slaves, the CRC commemorated a "collective action as opposed to one heroic person" (Harris 2001, 10). In this way, anonymity facilitates the art of democratic writing, which supports collective intelligence in place of individual credit. In the first of its associational functions, then, anonymity works in precisely this way: it draws individuals out of their singular perspective and forces them to engage in public debate from an alternative, collaborative position.

Second, beyond forming collectives, anonymity also helps individuals and groups negotiate with broader publics in distinct and important ways. As both Publius and Yik Yak suggest, the effects of associational anonymity complicate the relationship between speech and speaker by disseminating responsibility differently within and between smaller collectives and the broader public sphere. Attending to that complexity will help provide nuance to discussions of anonymity's role in contemporary public life, revealing the challenges inherent in the associational practices of democratic politics. Anonymity, especially when used collectively, disrupts the narrow chain of accountability that ties actions to distinct individuals and thus invites reconsideration of the mechanisms of responsibility that underlie democratic politics.

In the case of Yik Yak, for example, associational anonymity highlights the need to consider alternative mechanisms of accountability that are appropriate even for the anonymous spaces of public life. Approaching the question of racist and sexist speech on Yik Yak through this associational lens, for example, might have opened additional ways of addressing the app's influence on college campuses — beyond merely banning or blocking it. Universities could have 
taken more seriously how anonymity opened spaces for multiple kinds of groups and experimented with ways of preserving the associational opportunities provided by the platform, while enhancing debate and contestation both on and offline.

Because the discussions regarding Yik Yak largely took place within the protective frame, however, these kinds of insights were inaccessible. Moreover, the entrenchment of anonymity's protective frame has also led political theorists and practitioners to overlook or dismiss other existing models for digital democratic organizing. Platforms like Reddit, for example, utilize a system of up-and down-voting so that (pseudonymous) users can signal what is or is not acceptable according to the group norms of their digital space, while the Islands app uses geo-fencing and group moderation to build spaces for anonymous digital collaboration on college campuses (Cakebread 2017). Thus, as has been argued elsewhere (Forestal 2017), looking beyond traditional naming conventions associated with democratic accountability opens up novel architectural solutions that site designers might use to foster community norms that support productive democratic engagement.

These alternative structures will not be immediately or wholly successful. As we have noted all along, anonymity — even in its associational dimension - is not straightforward in its effects; it can just as easily support the collaborative work of the KKK as it can the Combahee River Collective. But when we look beyond the protective framing that dominates contemporary discussions of anonymity to investigate and integrate its associational potential, we can more fully appreciate the democratic value of anonymous civic engagement. We can, moreover, begin to identify and address the challenges that attend democratic practice. 


\section{Bibliography}

Abbott, Philip. 1996. "What's New in the 'Federalist Papers?"” Political Research Quarterly 49 (3): $525-45$.

Abernathy, Claire, Kevin M. Esterling, Justin Freebourn, Ryan Kennedy, William Minozzi, Michael A. Neblo, and Jonathan A. Solis. n.d. "Constituent Communication Through Telephone Town Halls: A Field Experiment Involving Members of Congress.” Le gislative Studies Quarterly 0 (0). Accessed June 13, 2019. https://doi.org/10.1111/lsq.12242.

Adair, Douglass. 1944. "The Authorship of the Disputed Federalist Papers: Part II." The William and Mary Quarterly 1 (3): 235. https://doi.org/10.2307/1923729.

1998. Fame and the Founding Fathers: Essays. Indianapolis: Liberty Fund.

Akdeniz, Yaman. 2002. “Anonymity, Democracy, and Cyberspace.” Social Research 69 (1): $223-$ 37.

Allen, D. 2015. Our Declaration: A Reading of the Declaration of Independence in Defense of Equality. Liveright Publishing Corporation.

Arendt, Hannah, and Jerome Kohn. 2006. Between Past and Future. Penguin Classics.

Arneil, Barbara. 2010. "Social Decline and Diversity: The Us versus the Us's." Canadian Journal of Political Science 43 (2): 273-87.

Asenbaum, Hans. 2018a. "Anonymity and Democracy: Absence as Presence in the Public Sphere." American Political Science Review, 1-14.

- 2018b. "Cyborg Activism: Exploring the Reconfiguration of Democratic Subjectivity in Anonymous." New Media \& Society 20 (4): 1543-63.

Ball, Terence, ed. 2003. The Federalist with Letters of "Brutus." Cambridge: Cambridge University Press.

Barendt, Eric. 2016. Anonymous Speech: Literature, Law and Politics. Bloomsbury.

Bartlett, Christopher, Gentile Douglas, and Chelsea Chew. 2016. "Predicting Cyberbullying from Anonymity." Psychology of Popular Media Culture 5 (2): 171-80.

Boudin, Chesa. 2011. "Publius and the Petition: Doe v. Reed and the History of Anonymous Speech." The Yale Law Journal 120 (8): 2140-81.

Boyd, Richard, and Laura K. Field. 2016. "Blind Injustice: Theorizing Anonymity and Accountability in Modern Democracies." Polity 48 (3): 332-58.

Brinker, David L., John Gastil, and Robert C. Richards. 2015. "Inspiring and Informing Citizens Online: A Media Richness Analysis of Varied Civic Education Modalities." Journal of Computer-Mediated Communication 20 (5): 504-19. https://doi.org/10.1111/jcc4.12128.

Cakebread, Caroline. 2017. "A New Messaging App Hopes to Learn Lessons from Yik-Yak and Become the next Big Thing on College Campuses." Business Insider, September 4, 2017.

Chernow, Ron. 2005. Alexander Hamilton. New York: Penguin Books.

Cobb, Jelani. 2016. "Where Is Black Lives Matter Headed?| The New Yorker." March 14, 2016. https://www.newyorker.com/magazine/2016/03/14/where-is-black-lives-matter-headed.

"College and Yik Yak Partner To Create Unique, Customized Local News Feed." 2015. UF College of Journalism and Communications. April 9, 2015. https://www.jou.ufl.edu/2015/04/09/college-and-yik-yak-partner-to-create-uniquecustomized-local-news-feed/.

Cornell, Saul. 1999. The Other Founders: Anti-Federalism and the Dissenting Tradition in America, 1788-1828. Chapel Hill, NC: University of North Carolina Press. 
Cullinane, Karen. 2011. "Protecting Anonymous Expression: The Internets Role in Washington." University of Michigan Journal of Law Reform 44 (4): 947-84.

Dewey, Caitlin. 2014. "How Do You Solve a Problem like Yik Yak?” Washington Post, October 7, 2014, sec. Internet Culture. https://www.washingtonpost.com/news/theintersect/wp/2014/10/07/how-do-you-solve-a-problem-like-yik-yak/.

Dewey, John. 1946. The Pubic and Its Problems: An Essay in Political Inquiry. Chicago: Gateway Books.

Dowling, Conor, and Amber Wichowsky. 2013. "Does It Matter Who's Behind the Curtain? Anonymity in Political Advertising and the Effects of Campaign Finance Disclosure." American Politics Research 41 (6): 965-96.

Ekstrand, Victoria Smith, and Cassandra Imfeld Jeyaram. 2011. "Our Founding Anonymity: Anonymous Speech During the Constitutional Debate." American Journalism 28 (3): 3560.

Electronic Frontier Foundation. 2016. "Recent Request for Guidance on Schools' Obligations under Title IX and Title XI," January 13, 2016. https://www.eff.org/files/2016/01/13/efflettertoocrfinal.pdf.

Feminist Majority Foundation et. al. 2015. Request for Guidance Reminding Schools of Obligations Under Title IX and Title VI to Address Sex-and Race-Based Harassment Occurring on Yik Yak and Other Anonymous Social Media Applications.

Fiesler, Casey. 2015. "How Missouri Could Demonstrate What's Wonderful About Yik Yak." Slate Magazine. November 12, 2015. https://slate.com/technology/2015/11/the-universityof-missouri-protests-and-yik-yak.html.

Forestal, Jennifer. 2017. "The Architecture of Political Spaces: Trolls, Digital Media, and Deweyan Democracy." American Political Science Review 111 (1): 149-61.

Forestal, Jennifer, and Menaka Philips. 2016. "Analysis | People Blame Facebook for Fake News and Partisan Bile. They're Wrong." Washington Post, December 16, 2016.

Frank, Jason. 2009. "Publius and Political Imagination." Political Theory 37 (1): 69-98.

- 2013. Publius and the Political Imagination. Rowman \& Littlefield Publishers Inc.

Furtwangler, Albert. 1984. 1984. The Authority of Publius. Ithaca: Cornell University Press.

Gardner, James A. 2011. "Anonymity and Democratic Citizenship." William and Mary Bill of Rights Journal 19 (4): 927-57.

Harris, Duchess. 2001. "From the Kennedy Commission to the Combahee River Collective." In Sisters in the Struggle: African American Women in the Civil Rights-Black Power Movement, edited by Bettye Collier-Thomas and V. P. Franklin. NYU Press.

Hayes, Bob. 2014. "Hayes: Yik Yak Unveils Social Problems." The Daily Northwestern (blog). May 14, 2014.

Heins, Marjorie. 2010. “"The Right to Be Let Alone': Privacy and Anonymity at the U.S. Supreme Court.” Revue Francaise Detudes Americaines n 123 (1): 54-72.

Hess, Amanda. 2015. "The Upside of Yik Yak." Slate Magazine. March 10, 2015. https://slate.com/technology/2015/03/yik-yak-the-anonymous-messaging-app-with-aterrible-rep-is-actually-pretty-great.html.

Hess, Amanda, and Isaac Chotiner. 2015. "Don't Ban Yik Yak." Slate, October 28, 2015. http://www.slate.com/articles/technology/users/2015/10/yik_yak_is_good_for_university _students.html.

Iandoli, Luca, Ivana Quinto, Paolo Spada, Mark Klein, and Raffaele Calabretta. 2018. "Supporting Argumentation in Online Political Debate: Evidence from an Experiment of Collective 
Deliberation." New Media \& Society $20 \quad$ (4): 1320-41. https://doi.org/10.1177/1461444817691509.

Junco, Rey. 2015. "Yik Yak and Online Anonymity Are Good for College Students." WIRED, March 17, 2015.

Larimer, Sarah. 2015. "Man Charged in Mizzou Yik Yak Threats Had Interest in Oregon College Shootings, Police Say." Washington Post, November 12, 2015, sec. Grade Point. https://www.washingtonpost.com/news/grade-point/wp/2015/11/12/police-say-mancharged-in-mizzou-yik-yak-threats-had-interest-in-oregon-college-shootings/.

Leitner, John M. 2015. "Anonymity, Privacy, and Expressive Equality: Name Verification and Korean Constitutional Rights in Cyberspace.” Journal of Korean Law 14 (2): 167-212.

Lupia, Arthur, and Anne Norton. 2017. "Inequality Is Always in the Room: Language and Power in Deliberative Democracy." Daedalus 146 (3): 64-76.

Maese, Rick, and Kent Babb. 2015. "Missouri Football Players Threaten to Boycott Season amid Racial Tension." Washington Post, November 8, 2015, sec. Sports. https://www.washingtonpost.com/sports/missouri-football-players-threaten-to-boycottseason-amid-racial-tension/2015/11/08/5c11c456-8641-11e5-9a07453018f9a0ec_story.html.

Mahler, Jonathan. 2015. "Who Spewed That Abuse? Anonymous Yik Yak App Isn't Telling." The New York Times, March 8, 2015.

Mill, J.S. 1977. Essays on Politics and Society. Vol. 18. 33 vols. Collected Works of John Stuart Mill. Toronto: University of Toronto Press.

Moore, Alfred. 2018. "Anonymity, Pseudonymity, and Deliberation: Why Not Everything Should Be Connected." Journal of Political Philosophy 26 (2): 169-92.

NAACP v. Alabama Ex Rel. Patterson 357 U.S. 449. 1958, 357 US 449.

Neblo, Michael A., Kevin M. Esterling, and David M. J. Lazer. 2018. Politics with the People: Building a Directly Representative Democracy. Cambridge University Press.

Pew Research Center. 2018. "An Analysis of \#BlackLivesMatter and Other Twitter Hashtags Related to Political or Social Issues." Activism in the Social Media Age. https://www.pewinternet.org/2018/07/11/an-analysis-of-blacklivesmatter-and-othertwitter-hashtags-related-to-political-or-social-issues/.

Putnam, Robert. 2000. Bowling Alone: The Collapse and Revival of American Community. New York: Simon and Schuster.

Ramkumar, Amrith, and Rachel Chason. 2015. "Updated: Same-Sex Kiss-in Staged at Myrtle Beach Club | The Chronicle." The Chronicle, May 6, 2015.

Ridout, Travis N, Michael M Franz, and Erika Franklin Fowler. 2015. "Sponsorship, Disclosure, and Donors: Limiting the Impact of Outside Group Ads." Political Research Quarterly 68 (1): 154-66.

Rösner, Leonie, and Nicole C. Krämer. 2016. "'Verbal Venting in the Social Web: Effects of Anonymity and Group Norms on Aggressive Language Use in Online Comments." Social Media + Society 2 (3): 1-13.

Rowe, Ian. 2015. "“Civility 2.0: A Comparative Analysis of Incivility in Online Political Discussion' I." Information, Communication \& Society 18 (2): 121-38.

Safronova, Valeriya. 2017. "The Rise and Fall of Yik Yak, the Anonymous Messaging App." The New York Times, May 27, 2017, sec. Style. https://www.nytimes.com/2017/05/27/style/yik-yak-bullying-mary-washington.html. 
Saveski, Martin, Sophie Chou, and Deb Roy. 2016. "Tracking the Yak: An Empirical Study of Yik Yak." MIT Media Lab, March.

Scigliano, Robert. 2000. The Federalist: A Commentary on the Constitution of the United States. New York: Modern Library.

Shalev, Eran. 2003. "Ancient Masks, American Fathers: Classical Pseudonyms during the American Revolution and Early Republic." Journal of the Early Republic 23 (2): 151-72.

Sheehan, Colleen A. 2004. "Madison v. Hamilton: The Battle over Republicanism and the Role of Public Opinion." The American Political Science Review 98 (3): 405-24.

Stoller, Eric. 2015. "Don't Ban Yik Yak." Inside Higher Ed, January 22, 2015.

Suler, John. 2004. "The Online Disinhibition Effect." Cyber Psychology \& Behavior 7 (3): 32126.

Talley v. California 362 U.S. 60. 1960, 362 US 60.

Tocqueville, Alexis de. 2006. Democracy in America. Edited by J. P. Mayer. Translated by George Lawrence. Harper Perennial Modern Classics edition. New York: Harper Perennial Modern Classics.

Warner, Michael. 1992. Letters of the Republic: Publication and the Public Sphere in EighteenthCentury America. Cambridge, MA: Harvard University Press.

Warren, Mark E. 2001. Democracy and Association. Princeton University Press.

Wethers, Lauren. 2016. "Yes, Tulane Has a Race Problem." The Tab Tulane (blog). February 11, 2016.

Wong, Wendy H, and Peter A Brown. 2013. "E-Bandits in Global Activism: WikiLeaks, Anonymous, and the Politics of No One." Perspectives on Politics 11 (4): 1015-33.

Zerilli, Linda. 2009. “Towards a Feminist Theory of Judgment.” Signs 34 (2): 295-317. 